\title{
METABOLOMICS IN THE STUDY OF ALZHEIMER'S DISEASE
}

Clara Ibáñez, Alberto Valdés, Virginia García-Cañas and Carolina Simó*

Laboratory of Foodomics, Institute of Food Science Research (CIAL), CSIC. Nicolás Cabrera 9, 28049 Madrid, Spain

*Corresponding author: Carolina Simó. E-mail: c.simo@csic.es

\begin{abstract}
With an increasing aging population, Alzheimer's disease (AD) has become a social and economic problem to societies worldwide, affecting millions of people. However, pathophysiological events associated with $\mathrm{AD}$ are not well elucidated yet and current definitive diagnosis is only obtained after death through examination of brain tissue. In the last years, Metabolomics has been demonstrated to provide deep insights into the full complexity of the disease phenotype and has been established as a promising approach to provide disease-specific metabolite signatures. The incipient application of Metabolomics may potentially contribute in the elucidation of $\mathrm{AD}$ physiopathological processes and ideally may offer therapeutic/preventing mechanisms to slow or reverse AD progress. In this chapter non-targeted metabolomics approaches applied to AD investigation are described.
\end{abstract}

\section{KEYWORDS}

Metabolomics, Alzheimer's disease, Profiling, Fingerprinting, Mass Spectrometry, Nuclear Magnetic Resonance. 


\section{TABLE OF CONTENTS}

\section{INTRODUCTION}

\section{METABOLOMICS IN AD}

2.1. Metabolomics and $\mathrm{AD}$ in $\mathrm{CSF}$

2.2. Metabolomics and AD in plasma and serum

2.3. Metabolomics and $\mathrm{AD}$ in post-mortem brain tissue

3. CONCLUSIONS AND FUTURE RESEARCH 


\section{INTRODUCTION}

Alzheimer's disease (AD) is the most prevalent form of late-life mental failure in humans $[1,2]$. It is expected that $\mathrm{AD}$ incidence will triple over the next 50 years [3]. AD pathology affects the central nervous system (CNS) leading a progressive destruction and atrophy of brain cortex especially those regions related to superior mental functions. Namely, neocortex and hippocampus areas are primarily affected in $\mathrm{AD}$ [4]. Clinically $\mathrm{AD}$ is characterized by the presence of intracellular neurofibrillary tangles (NFT) composed of hyperphosphorylated tau proteins [5] and $\mathrm{A} \beta$ peptide aggregates $(\mathrm{A} \beta)$ in form of extracellular amyloid plaques [6] and amyloid infiltrates in the brain microvasculature [7]. These formations are considered key factors in neuronal dysfunction and cell death [8-10]. Other neuropathological hallmarks for AD include synaptic loss and/or dysfunction, diminished neuronal metabolism and loss of multiple neurotransmitter systems [1]. These alterations in the CNS bring about an unspecific symptomatology that begins with cognitive deficits to remember autobiographical events specific to a time and place [11]. As the pathology advances to cortical brain areas the long-term memory becomes impaired and ordinary abilities including semantic memory and attention are affected leading to a dementia syndrome [12].

$\mathrm{AD}$ is preceded by a mild cognitive impairment (MCI) state followed by dementia, and it has been indicated that the annually conversion rate from MCI to dementia is about $15 \%$ [13] and reach up to $80 \%$ in a 6 years follow-up [14]. MCI is defined by a cognitive decline greater than expected for certain age and education level, but not severe enough to be considered dementia or to interfere notably with activities of daily life [13]. This condition is characterised by memory impairment that can be proved and diagnosed by objective measures [15]. Up to date, there is no clinical method to determine which patients with MCI will progress to dementia except for a long clinical follow-up [16]. The speed and severity of clinical progression after MCI diagnosis vary and depend on multiple factors, most not well elucidated yet. For instance, depression has been proposed as a risk factor for dementia and cognitive decline [17], postulated as causal effect by means of hippocampal damage [18] or as a possible prodromal state [19] of MCI state. There is a great clinical need to identify incipient AD in patients with $\mathrm{MCI}$ and many efforts are being made in the discovery of predictor markers of progression via the use of cognitive tests [20,21], structural and functional neuroimaging [12,22,23], CSF analysis [24,25], and other biomarkers, either isolated or in combination [26,27]. On the other hand, the USA National Institute of Aging and the Alzheimer's disease Association is working on the determination of the best predictor factors in the progression from normal cognition (presymptomatic or preclinical state) to MCI [28]. Some of the proposed research criteria and markers for preclinical AD are summarized in Fig. 1 [28]. These initiatives are extremely 
important since there is evidence suggesting AD pathological processes begin years or even decades before dementia onset [29].

Leaving aside the detection and identification of the pre-dementia states, even the diagnosis of patients suffering an advanced $\mathrm{AD}$ needs to be improved. $\mathrm{AD}$ is routinely diagnosed following the criteria established in 1984 by the National Institute for Neurological and Communicative Disorders and Stroke/Alzheimer's Disease and Related Disorders Association (NINCDS/ADRDA, now known as Alzheimer's disease Association) criteria [30]. These criteria establish that $\mathrm{AD}$ can exclusively be diagnosed with certainty at autopsy. A definitive $\mathrm{AD}$ diagnostic is only achieved with the detection of NFTs and $\mathrm{A} \beta$ in post-mortem brain tissue [31]. Nonetheless, CSF is considered a valuable source of AD biomarkers, very promising for the early detection and progress evaluation of AD [32]. Several markers, generally protein molecules, have been already linked to $\mathrm{AD}[33,34]$. Until date, the ratio between total tau protein and A $\beta$ peptide levels in CSF has been proposed as a high sensitive measure for diagnostic purposes for advanced $\mathrm{AD}$ patients, which in combination with brain imaging techniques is able to diagnose up to $90 \%$ of advanced $\mathrm{AD}$ patients, assuming a high economic burden per evaluated subject (ca. 6,000-10,000 euros approximately) [35]. NINCDS/ADRDA criteria includes standard comprehensive assessment protocol including clinical examination, brain imaging, electroencephalography, analyses of blood and CSF (including total tau, phospho-tau, and $A \beta_{1-42}$ ) and a detailed neuropsychological evaluation to diagnose $\mathrm{AD}$. If after these tests it is considered that the subject suffers mild-to-moderate $\mathrm{AD}$, different therapeutic options are possible. Currently, there is no remedy for AD but symptomatic therapy. Most recommended medications for mild-to-moderate $\mathrm{AD}$ include cholinesterase inhibitors (donepezil, rivastigmine or galantamine) that increase the levels of acetylcholine in the brain. However controversy about the satisfactory results [36] or limited benefits [37] of these drugs has been reported [38]. A combination of cholinesterase inhibitors with memantine (N-methyld-aspartate (NMDA) receptor antagonist) seems to produce consistent benefits in moderate-tosevere $\mathrm{AD}[39,40]$ with respect to a single drug administration. The search for therapeutic treatments at all phases of cognitive decline is imperative since up to date, no drug can reverse pathological process of this chronic disease. On the other hand, there are evidences suggesting that concurrent pharmacologic and behavioral methods may exploit functional benefits for patients suffering from dementia [41,42]. Although no specific disease-modifying treatment has yet been shown to be effective for dementias, it is particularly important to develop effective, targeted treatments to halt or delay the onset of cognitive decline from preclinical and MCI states to $\mathrm{AD}$ related dementia. An accurate identification of $\mathrm{AD}$ cases at MCI state or, even better at preclinical state, might enable early therapeutic interventions to reduce considerably, 
stop or even reverse the numerous pathological, emotional and economic costs of the illness [43].

The distinction of preclinical $\mathrm{AD}$ stage from changes of normal ageing represents a major demand in $\mathrm{AD}$ investigation. Unlike MCI state, diagnostic criteria for this prodromal phase have not yet been established. In this sense, one of the main focuses of the scientific community is to elucidate the link between the neurodegenerative cascade of $\mathrm{AD}$ and the apparition of first clinical symptoms. At the same time, the lack of effective therapeutic treatment for AD entails an ethical conflict in the preclinical stage diagnosis because of the potential emotional repercussion. The discovery of biomarkers suitable to monitor the evolution and progression from the preclinical phases to $\mathrm{MCI}$ related to $\mathrm{AD}$ is particularly challenging and may offer key information to deepen in the origin, causes and pathophysiology of $\mathrm{AD}$. The detection of $\mathrm{AD}$ biomarkers can be achieved via two different approaches: knowledge-based and unbiased. The traditional one consists of the "knowledge-based" or targeted (deductive method) approach and relies on a direct understanding of the neuropathological processes. Until date several studies have targeted protein biomarkers related to AD pathology, among which beta-amyloid peptide and its precursor (amyloid precursor protein, APP) stands out [44-46] followed by the analysis of other proteins such as tau $[47,48]$ or BACE ( $\beta$-site APP cleaving enzyme-1) [49,50]. From a genetic point of view, allelic variation of ApoE has been described as the most influential genetic risk factor to develop sporadic $\mathrm{AD}$ [51]. To a lesser extent, cholesterol [52,53] or homocysteine [54] have also been targeted as potential metabolic AD biomarkers. The great lack of knowledge of pathophysiological processes that govern $\mathrm{AD}$ makes the alternative "unbiased" approach more suitable than the targeted approach in the generation of new hypothesis [55] about the origin, causes and progression of AD. In contrast to targeted analysis of selected analytes, the goal of untargeted approach is to find biomarkers through the comprehensive study of the maximum number of molecules in a biological system. The use of omics technologies in biomarker discovery has evolved from traditional targeted to non-biased approaches. Omics technologies refer to a group of advanced analytical technologies used in a high-throughput manner to explore the composition, roles, and relationships of a variety of molecules in a biological system. Omics are able to significantly improve the experimental models that offer only a temporal snapshot of the huge complexity and dynamic nature of biological networks that govern human health and disease [56]. Thus, Transcriptomics [57], Proteomics [33,34] and Metabolomics [58-61] technologies have been applied in AD research and they are expected to significantly help in the advance of the investigation of biomarkers implicated in the pathogenesis of AD [62]. 


\section{METABOLOMICS IN AD}

The development of new methodologies to discover early and high confident biomarkers related to $\mathrm{AD}$ progression is compulsory. This investigation will contribute to reveal mechanisms by which neurodegeneration starts and progresses, so far unknown [63]. Among omics technologies, Metabolomics intensifies variations occurring both in the proteome and the genome, and represents a faithful reflection of the organism phenotype in health and disease [59]. Metabolomics, the newest of the omics technologies, deals with the comprehensive study of the metabolome or the entire set of small molecules (about $<1500 \mathrm{Da}$ ) in a biological system (cell, biofluid, tissue, or organism) at a time, under given conditions [64]. The metabolome corresponds to the end stage of all molecular events owing to gene variation and expression (genomics), protein expression and modification (proteomics), and environmental exposures in a biological sample [65]. Massive and high-throughput determination of metabolites in complex samples is a powerful tool to characterize organism phenotypes and to discover biomarkers for health/disease states [66]. Metabolomics is increasingly applied to AD investigation [67] due to the complex nature of the disease. In fact, increasing evidences suggest that $\mathrm{AD}$ is a heterogeneous and multifactorial disorder resulting from combination between the genetic susceptibility and environmental influences [68] including life-style factors [69]. Biological processes such as inflammation, cholesterol metabolism, oxidative stress and homocysteine homeostasis have been observed to be different in $\mathrm{AD}$ patients compared to control subjects in "knowledge-based" approaches, but these biomarkers did not achieved sufficient discriminatory power [70]. Since the causes of this neurological disease are still not clear, non-targeted Metabolomics opens new frontiers in $\mathrm{AD}$ investigation. The unbiased nature of these metabolomic strategies require especial attention on study design since metabolites have very different molecular structures (lipids, carbohydrates, nucleic acids, amino acids, organic acids and others) and are present in biofluids and tissues in a wide dynamic range of concentrations (pmol-mmol) [71]. Therefore the complete analysis of entire metabolome in biological systems is still challenging and no single analytical platform can cover the entire metabolic signature of a given biological sample. Mass spectrometry (MS) and nuclear magnetic resonance (NMR) are by far the two analytical platforms most predominantly used in Metabolomics. NMR permits the analysis of complex mixtures of metabolites with little or no sample preparation in a rapid and non-destructive way [72] and has been largely applied in Metabolomics [73]. NMR was firstly used in AD Metabolomics in 1993 [74], 9 years before than the application of the first MS-based metabolomics study [75]. This analytical approach has been applied in AD investigation in a variety of applications as can be seen in Table 1. For instance NMR has been used to uncover $\mathrm{AD}$ metabolic biomarkers involved in specific metabolic pathways such as oxidative [76], lipid [77] and cholesterol [78] metabolism. 
Compared to NMR, MS technique is highly sensitive enabling broader surveys of the metabolome and provides spectral information for the identification process of metabolites [79]. The use of ultra-high resolution mass spectrometers (e.g., TOF, FT-ICR MS, Orbitrap ${ }^{\circledR}$ ) is essential in MS-based metabolomics approaches, to obtain accurate mass measurements for the determination of elemental compositions of metabolites and for their tentative identification with the help of metabolite databases [80]. On the other hand, $\mathrm{MS}^{\mathrm{n}}$ experiments provide additional structural information for metabolite identification purposes, especially when product ions are analysed at high resolution (with Q-TOF, TOF-TOF, or LTQ-Orbitrap). Evaluation and comparison of NMR and MS analytical platforms on the application in Metabolomics have been extensively studied [79-82]. Both analytical platforms can be used as a standalone or in combination with previous separation techniques such as gas chromatography (GC), liquid chromatography (LC) or capillary electrophoresis (CE). The human metabolome include a great portion of polar compounds such as polyamines, amino acids or simple sugars. Compared to GC, both LC and CE can make possible the separation of higher polarity compounds and represent the two separation techniques most useful for medium to highly polar metabolic profiling. On the other hand, GC is especially suitable for the analysis of organic molecules and generally requires sample derivatization of metabolites to create volatile compounds.

Two different and complementary analytical strategies are basically followed in non-targeted Metabolomics: metabolic "fingerprinting" and "profiling". "Metabolic fingerprinting" has been proposed as a means of analyzing the total set of metabolites, avoiding biases against certain classes of compounds, for sample classification $[83,84]$ and "metabolic profiling" is referred to identification and quantification of a predefined group of metabolites (chemically related metabolites or associated with a particular metabolic pathway) [64]. Metabolic fingerprinting is gaining extensive interest across a wide variety of disciplines with the emerging main focus on biomarker discovery for disease prognosis, diagnoses and therapy monitoring [85]. This approach offers a rapid biochemical snapshot of the metabolome [84] with the possibility of correlating the perturbations from the homeostatic or healthy state with disease. Moreover, metabolic fingerprints reveal characteristic metabolic patterns broadening our understanding of unknown pathological processes [86], which enhance its utility in AD biochemical alterations. In an ideal metabolic fingerprinting approach, metabolite extraction method and analytical platform should not be biased towards any group of molecules. In practice, these issues have not been resolved yet but tried to be minimized. The broad information obtained by metabolic fingerprinting approach make it the most attractive and suitable strategy for biomarker discovery [85], while at the same time, represents the most challenging and time-consuming approach in Metabolomics. In AD research, the obtaining of metabolic fingerprints is a recent practice by using both NMR [87-89] and MS-based [90-94] techniques. 
Metabolic profiling approaches are developed for the determination and quantitation of metabolites of a particular pathway or for a class of compounds. This strategy generates quantitative information of metabolites belonging to known biochemical pathways and physiological interactions [95]. Using metabolic profiling, optimized analytical design (sample treatment, analytical platform, etc.) for a group of compounds is performed optimizing sensitivity and specificity for the group of molecules of interest. The information obtained from the metabolic profiles not only describes the metabolic state of a certain sample but in many cases is used for comparison purposes.

The combination of characteristics from both metabolic profiling (generally, a hypothesisdriven approach) and metabolic fingerprinting (hypothesis-generating approach) represent a powerful and highly complementary methodology. In fact it can be especially useful to get the benefit from the potential to discover novel unforeseen metabolic factors or biomarkers in fingerprinting approaches with the option of demonstrating the observed changes of known metabolites or confirming the potential biomarkers by means of the metabolic profiling mode [96]. A recent study followed this comprehensive metabolomics approach in the investigation of biomarkers for $\mathrm{AD}$ by the comparison of postmortem brain tissue from $\mathrm{AD}$ patients and healthy control subjects [97]. First, a metabolic fingerprint to determine potential biomarkers and affected pathways in $\mathrm{AD}$ pathology was performed. Then the specific metabolic pathway related to potential $\mathrm{AD}$ biomarkers spermine and spermidine, namely biogenic polyamine metabolism, was explored in detail finding three more molecules altered due to AD pathology [97].

Although Metabolomics is still in its infancy in AD investigation, a number of studies have been published in the last years (Table 1), as this chapter will show. Most of them are based on the analysis of CSF, blood or post-mortem brain tissue samples, although in a lesser extent, urine has been also examined in the search of AD biomarkers [89,98].

\subsection{Metabolomics and $\mathrm{AD}$ in $\mathrm{CSF}$}

Metabolomics works focused on AD investigation are mostly based on the analysis of CSF. Main reason is that CSF composition is directly affected by the CNS. Therefore, alterations due to AD pathology will be more probably observed in this sample than in other biofluids. The role of CSF includes a mechanical protection of CNS against trauma, and transport of nutrients to ensure the homeostasis of CNS cells [99].

Prior to metabolomic analysis sample treatment is typically needed since CSF contains approximately $0.3 \mathrm{mg} / \mathrm{mL}$ protein [100] that may hinder metabolite analysis. Consequently, CSF sample treatment is essentially directed to protein removal by means of organic solvent 
addition $[92,101]$ or by ultrafiltration $[93,102,103]$. The final metabolic extract composition will depend in a great extent on the sample treatment [104] and it will be selected mostly regarding the metabolomic approach and the analytical technique that will be afterwards applied.

In some metabolic applications an additional step of purification is needed. For instance, Myint et al., [105] removed CSF protein content using $5 \mathrm{kDa}$ centrifuge filters and then an additional step of solid phase extraction (SPE) through a polymeric sorbent was carried out to purify hydrophilic metabolites. In that study, analysis of CSF samples from AD diagnosed subjects $(n=18)$ and healthy controls $(n=18)$ was carried out by the development of a new chromatographic method based on nanoLC-Q/TOF in the positive ionization mode. By using multivariate analysis satisfactory separation was obtained among two groups of subjects using PCA statistics [105]. In that study, an extensive optimization of stationary phases for separation of weak and strong cationic metabolites was required.

When we speak about the type of metabolic species covered by a certain technique, it is also worth mentioning that the analysis of polar metabolites is specially challenging in Metabolomics. CE is a fast and high-resolution separation technique especially suitable for the separation of ionic and highly polar molecules that cannot be easily obtained by LC [104] and has been applied in the investigation of early biomarkers related to AD progression, from MCI and healthy states $[93,102]$. According to a previous statement that considered free amino acids as important molecules in neurotransmission, receptor function and implicated in neurotoxicity [106] Samakashvili et al. determined chiral amino acid alterations in progression to AD. For that purpose a micellar electrokinetic chromatography (MEKC) with $\beta$-cyclodextrin as a chiral selector and laser induced fluorescence (LIF) detection, was developed. This enantioselective method permitted the determination of 11 amino acids in CSF samples from healthy subjects, MCI patients who progressed to AD in a two years follow-up period, MCI patients without progression to $\mathrm{AD}$ in that follow-up period, and $\mathrm{AD}$ patients. Decreased levels of L-Arginine, L-Glutamic acid, L-Aspartic acid and L-Lysine, and increased levels of gamma-amino butyric acid were related to the progression of MCI patients to AD [102] and were suggested as potential early biomarkers. The concept of early diagnostic biomarkers has a long history, with many studies showing that $\mathrm{AD}$ biomarkers can be used to predict conversion from MCI to AD. As stated in introduction section still now the clinical diagnosis of $\mathrm{AD}$ requires the presence of MCI state [107] and up to date, there is no clinical method to determine which MCI cases will progress to $\mathrm{AD}$ except for a long clinical follow-up period [43]. The discovery of markers that indicate progression from MCI to $\mathrm{AD}$ is still an unresolved issue, and a topic of high relevance in $\mathrm{AD}$ research. Several groups have been addressed this issue using metabolomic approaches in CSF samples. Thus, CSF metabolic fingerprints from patients showing different cognitive status related to AD were obtained by CE-MS [93]. In that study 85 CSF samples were obtained from 
individuals in four different cognitive states, namely age-matched controls, patients who at the sample collection time suffered from MCI, and finally a group of AD patients. After a clinical follow-up period of two years, some patients with MCI developed AD and others remained stable. After CE-MS analysis and extensive data processing (peak detection, filtering, migration time alignment, normalization, etc.) 71 metabolites were detected in the 85 samples. As a result of the multivariate statistical analysis, a $90 \%$ of correct sample assignment was achieved with the determination of 10 potential metabolic biomarkers [93]. The most similar metabolic fingerprints were observed when MCI patients without development to AD and control subjects were compared. That finding led to the merger of these two groups of samples as one "non-AD" sample group and other discriminant analysis was performed reaching up to $97 \%$ of correct assignment with the determination of 14 potential metabolic markers. Increased levels of choline and a decreased concentration of carnitine and creatine were observed in MCI patients who progressed to AD compared to the other groups of samples under study [93]. UHPLC-MS analytical platform was used to improve metabolome coverage of CSF samples [103]. Thus, by using RP/UHPLC-MS and HILIC/UHPLC-MS, and a subsequent data processing, a total of 524 high-confident metabolites were detected in CSF samples. After a discriminant analysis, a 98.7\% correct assignment was achieved with the determination of 17 significantly different metabolites among the four groups of samples (control, MCI with progression to AD, MCI without progression to $\mathrm{AD}$ and $\mathrm{AD}$ ). Furthermore values above $95 \%$ for sensitivity and specificity were obtained. In MCI patients who progressed to $\mathrm{AD}$, decreased levels of a neuroprotective metabolite as taurine and increased levels of neurotoxic metabolites such as dopamine-quinone or methylsalsolinol were observed [103]. A less common analytical approach in Metabolomics, HPLC with electrochemical array detection (ECA), has been applied to study metabolic signatures from $114 \mathrm{CSF}$ samples from three groups of patiets: 40 control individuals (healthy), 36 subjects with MCI and 38 AD patients [108]. ECA is an extremely selective and sensitive detection technique with simpler and cheaper instrumentation, but compared to NMR or MS, less structural information is obtained by LC-ECA. Before analysis, CSF proteins were precipitated by methanol addition and metabolic fraction was then analyzed by LC-ECA. As a result 21 of a total of 71 detected metabolites could be identified by the analysis of reference standard mixtures. Patients presenting AD and MCI showed elevated levels of methionine, whereas the methionine/reduced glutathione ratio was decreased, suggesting a glutathione depletion associated with AD pathology [108]. In that work a correlation between metabolite levels and concentration of $\mathrm{A} \beta_{1-42}$, total tau and phospho-tau proteins in CSF was carried out. As a result, an association between the levels of vanillylmandelic acid and xanthine with total-tau protein in CSF was found, inferring that norepinephrine pathway and purine pathway may be involved in total tau aggregation and pathology generation [108]. Later, the same research group in collaboration with other 
laboratories combined the metabolic information obtained by HPLC-ECA with that obtained from GC-TOF MS platform [109]. In that work $40 \mathrm{AD}$ patients and 38 healthy control subjects were considered. After the GC-TOF MS analysis and statistical evaluation, higher levels of two metabolites showed the most consistent association with the disease. However authors declared that unknown identity of these two metabolites hinders biological interpretation [109].

Other study that deepened in the disease phenotype by means of the comparison of $\mathrm{AD}$ and healthy subjects was published by Czech et al., in 2012 [92]. CSF samples from 79 AD patients and 51 age-matched controls were studied. CSF deproteinization and metabolite fractionation (polar and no polar metabolites) was accomplished by using a mixture of ethanol and dichloromethane. Polar and no polar metabolic fractions were analyzed by GC-MS and LCMS/MS, respectively. More than 340 metabolites were determined. After statistical analysis an interesting finding was highlighted: by using univariate statistical analysis female AD patients showed more significant changes than male AD patients, compared to control subjects. Cysteine, uridine, cortisol, 3-methoxy-4-hydroxy phenylglycol, dopamine, noradrenaline and normetanephrine were significantly different in $\mathrm{AD}$ patients compared to control group. Then, discriminant analysis showed cysteine and uridine as the best metabolite pair to predict AD with sensitivity and specificity values of $75 \%$ (Fig. 2) [92]).

The assessment of metabolic changes related to the beginning and progress of AD could improve the diagnosis and monitoring of $\mathrm{AD}$ but, in a more challenging scope, metabolic patterns could even help to evaluate the risk of healthy people to develop the disease in the future or the detection of subjects in the prodromal state of the disease. As stated in the introduction section, the investigation of early biomarkers of the long preclinical stage of $\mathrm{AD}$ could improve our understanding on $\mathrm{AD}$ pathophysiology including the development of new therapeutic targets to revert AD pathology. Focused on this idea, Jukarainen et al. analyzed CSF samples from 44 neurological controls who did not present any sign of dementia or chronic neurological diseases [90]. Subjects were divided into two groups consisting of 10 individuals who presented a typical concentration of $A D$ protein markers, namely reduced soluble $A \beta_{1-42}$ and increased tau concentrations in CSF, and 34 control subjects with normal levels of AD protein markers in CSF. After NMR analysis of the samples, a curve fitting method based on constrained total line shape method showed that 31 metabolites covered the $85 \%$ of the total spectral intensity. However, only one metabolite was significantly different between the two groups of subjects, namely creatinine was higher in CSF from subjects with typical AD markers concentrations [90].

One of the biochemical processes that have covered much of the research performed on AD over the last years is the oxidative stress mechanisms [110]. Mitochondrial dysfunction has been 
suggested to underlie AD pathophysiology [111]. Deposition of heavy metals and alteration of the mitochondrial functionality are some of the facts and effects of oxidative stress observed in AD process [112]. Given its importance, a number of reviews have tackled this complex topic [112-115]. To explore this aspect at metabolomics level, oxidative stress related metabolites were studied using a profiling approach [76]. Thus, CSF samples from 48 individuals (12 AD patients, 19 with multiple sclerosis and 17 control subjects) were analyzed by ${ }^{1} \mathrm{H}$ NMR. After collection CSF samples were lyophilized and no protein removal was required. In agreement with brain oxidative metabolism impairment, increased concentrations of several amino acids (alanine, lysine, valine, leucine or isoleucine, tyrosine and glutamine), acidic molecules (lactate and pyruvate) and inositol were found in AD samples [76].

\subsection{Metabolomics and AD in plasma and serum}

Lumbar puncture to obtain CSF can produce several side effects [116]. Headache lasting less than one week occurs in up to $40 \%$ of patients representing the most common complication after lumbar puncture. Occasionally it is accompanied by nausea, vomiting, vertigo, reduced hearing and blurred vision. Other complications, including headaches lasting from 8 days to 1 year, cranial neuropathies, continued backache, nerve root injury, and meningitis, are rare, following less than $1 \%$ of lumbar punctures [117]. In addition to these side effects, lumbar puncture is a complicated [118] and expensive procedure so other alternatives such as peripheral blood could be of interest in the search of biomarkers related to AD.

From the clinical point of view, there is a clear trend toward the analysis of minimum invasive samples (eg. blood or urine) for biomarkers search [119]. CSF is constantly exchanged and cleared via the blood [120]. This direct contact between CSF and blood encourages investigating this biofluid (plasma, serum and/or cells) which could reflect pathological changes in the brain [121]. However, exchanges between blood and CSF are not well elucidated yet and thus blood biomarkers usefulness is limited owing to the highly selective blood-brain barrier [70]. Since 2000s important efforts to find reliable AD biomarkers in peripheral blood following proteomic approaches have been carried out with moderate success [122]. In this sense, Metabolomics can be considered a relatively little explored technology, which may offer valuable information. Recently, Trushina et al. [123] established to what extent metabolic changes observed in CSF were or not reflected in plasma obtained from the same individuals. Metabolic fingerprints from CSF and plasma from AD ( $n=15)$, MCI $(n=15)$ and control $(n=15)$ individuals was compared to find the correlation between both biofluids and also to uncover biomarkers of AD progression. Integrated information from CSF and plasma samples was used to select and validate reliable plasma biomarkers related to AD [123]. As expected, the number 
of affected pathways in both biofluids increased with disease progression. Interestingly compared to control subjects near 30\% and $60 \%$ of the metabolic pathways altered in the CSF of MCI and $\mathrm{AD}$ patients respectively, were also affected in plasma samples from the same individuals showing certain correlation between biofluids [123]. Amino acid and dipeptide content correlation between CSF and plasma was also accomplished by Fonteh et al. including also urine in that case [98]. CSF, plasma and urine from 8 AD patients and 8 control subjects were submitted to metabolite extraction. Briefly the extraction of the compounds of interest of $200 \mu \mathrm{L}$ of CSF, $100 \mu \mathrm{L}$ of plasma and $200 \mu \mathrm{L}$ of urine was performed by a solid phase extraction and followed by derivatization. Amino acids and dipeptides were then detected by LC-MS/MS and differences between $\mathrm{AD}$ and control groups were determined in the three biofluids. As a result 23, 37 and 28 metabolites could be detected in CSF, plasma and urine respectively, and were compared between control and AD subjects. As can be seen in Fig. 3 [98] metabolic variations due to $\mathrm{AD}$ were very different among the three biofluids. Altered metabolites due to $\mathrm{AD}$ pathology were identified and related to different biochemical processes such as neurotransmission (L-Dopa and dopamine), urea cycle/detoxification or NO formation (arginine, citrulline, ornithine), inhibitory processes (glycine) and antioxidation (carnosine) [98].

With the aim to detect potential metabolite biomarkers of $\mathrm{AD}$ in plasma, Li et al. [91] compared the metabolic fingerprints obtained by UHPLC-MS, from 20 control subjects and $20 \mathrm{AD}$ patients. The statistical analysis by means of a PCA showed metabolic changes between AD and control samples mainly associated with nine potential biomarkers. Tryptophan, different lysophosphatidylcholines and sphingosines were highlighted as the metabolites that most differentiated $\mathrm{AD}$ from control groups of plasma samples [91]. In a different work, in order to monitor the progression markers to $\mathrm{AD}$, plasma samples from control, MCI without progression to $\mathrm{AD}$ (in a 1-4-year follow-up), MCI who progressed to $\mathrm{AD}$ (in that follow-up period) and $\mathrm{AD}$ diagnosed subjects was carried out [124]. In that work, two different analytical platforms were used to widen the metabolome coverage. GCxGC-MS method was developed for the analysis of amino acids, free fatty acids, ketoacids, organic acids, sterols and sugars, while UHPLC-MS was optimized for the determination of lipids [124]. As a result, 683 metabolites (139 lipids and 544 polar compounds) were determined. The high degree of co-regulation among the detected molecules was represented by clustering metabolites into subsets following the Bayesian model. 7 and 6 clusters were obtained for UHPLC- and GCxGC-based metabolomics data, respectively. An alteration of pentose phosphate pathway between the two groups of MCI patients (MCI with and without progression to $\mathrm{AD}$ ) together with an overall trend towards lower lipid levels in $\mathrm{AD}$ patients was observed [124]. Those samples with lower lipid contents were associated to processes linked to membrane lipid remodeling in AD patients. Lipids are not only major 
constituents of cell membrane physiology but are involved in crucial processes constituting one of the main focuses on Metabolomics. The vast majority of AD metabolic profiling studies of peripheral blood samples are focused on the investigation of lipid-related metabolites. Alteration in $\mathrm{AD}$ lipid metabolism has been suggested since brain tissue from $\mathrm{AD}$ patients display a higher occurrence of "adipose inclusions" or "lipoid granules", already observed by Alois Alzheimer when he first described the disease [125]. In fact, a close link between lipid metabolism and $\mathrm{AD}$ has been established when the $\varepsilon 4$ allele of the apolipoprotein $\mathrm{E}$ (ApoE) gene was identified as the strongest genetic risk factor for $\mathrm{AD}[126,127]$. ApoE encodes a 34 $\mathrm{kDa}$ protein that serves as a crucial regulator of cholesterol metabolism in the brain and of triglyceride metabolism throughout the body. The processes by which ApoE mediates the uptake of lipoprotein particles in the brain via the low-density lipoprotein (LDL) receptor related protein and the very low-density family lipoprotein receptor have been already reviewed and described in detail $[128,129]$. Several evidences suggest that systemic lipid levels associate more strongly with the development of AD than previously assumed [130] and may vary in the progression to $\mathrm{AD}$. To determine the molecular insights on the potential early lipid biomarkers, serum samples from $19 \mathrm{MCI}$ and 26 control subjects were studied [77]. To obtain information on three different groups of metabolites, namely lipoproteins, polar metabolites and lipids, three NMR approaches were optimized. Lipoproteins group was analyzed after the application of optimized NMR conditions to detect macromolecules (mainly lipoprotein lipids and albumin). To obtain information about polar metabolites macromolecules signals were suppressed by the application of a pulse sequence. Finally lipid signals were detected after the breakdown of lipoprotein particles. Information obtained from the three groups of metabolites was afterwards combined and correlated with clinical data reported from the individuals under study. Interestingly, vascular factors, metabolic syndrome and cognitive decline were shown to be closely interrelated. Furthermore lower omega-3 fatty acids, sphingomyelin and phosphatidylcholine appear to be associated with $\mathrm{AD}$ risk factors presence, in MCI patients [77].

Bile acids have also been highlighted as possible metabolic markers of AD progression through a metabolic fingerprinting approach [131]. Plasma samples from 10 control subjects, 12 MCI and $16 \mathrm{AD}$ patients were analyzed by UHPLC-MS/MS. After the PCA did not show any grouping of subjects by disease state, a partial least-squares discriminant analysis (PLS-DA) was applied showing separation for the three groups of samples. Increased levels of glycocholate, glycochenodeoxycholate and glycodeoxycholate were observed in MCI and AD patients. However, the unsuitability in the validation of the PLS-DA model for disease prediction and diagnosis was attributed by the authors to the high levels of inter- and intrasubject variability and the small number of samples. The same problem was considered in 
another study by Sato et al. [132] where plasma from 10 control subjects, $10 \mathrm{MCI}$ and $10 \mathrm{AD}$ patients were analyzed by LC-MS. Lysophopholipid (18:1) was revealed as potential early biomarker because was observed gradually decreased in the progression to $\mathrm{AD}$ [132].

Novel approaches such as the non-targeted multi-dimensional mass spectrometry-based shotgun lipidomics (MDMS-SL) has also been applied to study AD. By using MDMS-SL approach, plasma from $26 \mathrm{AD}$ patients and 26 cognitively normal subjects by ESI-QqQ MS were analyzed in the negative ion mode [133]. More than 800 lipid related molecular species from 9 classes of lipids (choline glycerophospholipid, lysophosphatidylcholine, ethanolamine glycerophospholipid, phosphatidylinositol, sphingomyelin, ceramide, triacylglycerol, cholesterol and cholesterol esters) were detected in plasma samples. Significant reductions of sphingomyelin and significant increase in ceramide content were observed in AD patients suggesting that the increased ceramide content might result from the accelerated sphingomyelins hydrolysis or increased biosynthesis in brain [133].

A number of epidemiological studies have shown a potential link between cholesterol lowering compounds, especially statins and a strongly decreased prevalence or incidence for dementia [134-136]. These evidences may indicate that targeting lipid metabolism [137] and more specifically cholesterol related metabolites in humans may be a potential strategy for AD prevention. Most predominant pathways related to clearance of key protein AD markers which are affected by cholesterol are described elsewhere [137]. For instance it was observed higher plasma cholesterol levels in individuals with the $\varepsilon 4$ allele of ApoE, which elevates the risk for early ( $<65$ years of age) AD onset [138]. In agreement with these findings, cholesterol has been highlighted in a recent study as a powerful biomarker for AD [139]. After a preliminary discovery and identification of demosterol and cholesterol as potential AD biomarkers, a LCMS method was optimized to quantify these two metabolites [139]. The analysis revealed that desmosterol was found to be decreased in AD vs. controls plasma. The developed analytical method to quantify desmosterol and cholesterol revealed that desmosterol and the desmosterol/cholesterol ratio were significantly decreased in $\mathrm{AD}$ patients. Results were confirmed with a validation group of 109 plasma samples from clinically well described patients.

\subsection{Metabolomics and $A D$ in post-mortem brain tissue}

Post-mortem brain tissue (BT) has brought about the main theories to explain origin and to design treatments for AD [140]. In contrast to plasma or CSF biofluids, the brain area or region of tissue must be carefully selected in the study design since metabolite composition is not 
homogeneous. Commonly affected regions in the brain include the association of cortical and limbic areas with especial damage of the cerebral cortex, certain subcortical regions and the hippocampus. Although amyloid plaques and NFTs are differentially distributed among AD patients, autopsies have shown predominance towards the temporal lobe. Contraction of cerebral cortex and hippocampus and increase of brain ventricles are other alterations observed in post-mortem brain tissue of $\mathrm{AD}$ patients. This complexity makes the majority of metabolomics studies to analyze several brain regions. For instance, post-mortem BT samples from frontal, parietal and occipital lobe from 10 control health subjects and $10 \mathrm{AD}$ patients have been studied by using a metabolomic approach [97]. Metabolite extraction was performed on frozen grinded samples by the addition of methanol and Tris- $\mathrm{HCl}$ as solvent and followed by ultrafiltration to discard macromolecules. Metabolic fingerprinting by UHPLC-TOF MS analysis was primarily used to evaluate the diversity of low-molecular-weight molecules patterns from the frontal, parietal and occipital lobes in the positive and negative ion modes. After a multivariate statistical analysis, a total of 431 metabolite species were selected to identify possible biomarker candidates based on all brain regions under study. Five possible biomarkers in the frontal and parietal lobe areas were observed. Among them, identity of spermine and spermidine was confirmed by comparison with chromatograms and MS spectra of commercial standards. With the aim to increase the sensitivity and selectivity toward polyamine analysis, a derivatization procedure was applied to all the brain tissue samples by using of 4(N,N-dimethylaminosulfonyl)-7-fluoro-2,1,3-benzoxadiazole (DBD-F). Then the analysis was performed by UHPLC-MS/MS [97]. As a result, other polyamines were uncovered linked to AD pathology: an increase of putrescine, acetylspermidine and acetylspermine in AD frontal lobes was observed. In that work, Authors suggested a new theory shown in Fig. 4 [97] based on the increase in the activity of ornithine-decarboxylase enzyme induced by the amyloid plaques and/or neurofibrillary tangles and the effects of polyamines on N-methyl-D-aspartate (NMDA) receptors in the AD brain. In a different work, UHPLC-MS was also the selected analytical platform [94] to study neocortex metabolic fingerprints from post-mortem BT of 15 AD patients and 15 control healthy subjects. After an orthogonal projection to latent structures-discriminant analysis (OPLS-DA) (Fig. 5) and a t-test, 34 and 32 candidate biomarkers were observed to be statistically different in the two groups of samples, in the positive and negative ion modes, respectively [94].

Polar biomarkers have also been investigated by NMR [88] in post-mortem BT samples. These samples were treated with perchloric acid and metabolic extracts were analyzed to compare AD with amyotrophic lateral sclerosis (ALS) [88]. After multivariate statistical analysis of the 8 AD and the 11 ALS samples, a high score in the statistical parameters of OPLS was obtained with the exclusion of one AD sample. Increased concentration of branched amino acids, alanine, 
acetate, glutamine, glutamate and glycerophosphocholine in AD patients was observed when compared to ALS [88].

One of the possibilities to overcome the difficulty to obtain BT samples is the use of animal models reproducing certain characteristics of the AD pathology. In this sense, numerous transgenic mouse models have been used in $\mathrm{AD}$ investigation. Most common mice used in $\mathrm{AD}$ investigation, express human mutant amyloid precursor protein (APP). There are APP mutants mice that develop robust amyloid plaque pathology (e.g. Tg2576 (K670N, M671L) and TgCRND8(KM670/671NL + V717F)), presenilin protein mutants (e.g. M146L) and biogenic transgenic mice that express not only mutant APP but also mutant presenilin protein (PS) (e.g. APP/PS1)[141-145]. Using APP mutants, metabolic fingerprints of eight different brain regions of TgCRND8 mice (5 young and 3 aged mice) and control mice (4 young and 5 aged mice) were obtained by NMR [87]. Decreased levels of N-acetyl-l-aspartate, glutamate, glutamine, taurine (exception hippocampus), $\gamma$-amino butyric acid, choline and phosphocholine, creatine, phosphocreatine and succinate were observed in hippocampus, cortex, frontal cortex (exception $\gamma$-amino butyric acid) and midbrain of transgenic animals. Moreover, an increase in lactate, aspartate, glycine (except in midbrain) and other amino acids including alanine (exception frontal cortex), leucine, isoleucine, valine and water soluble free fatty acids were observed in the TgCRND8 mice. Furthermore, the combination of histological and metabolic data demonstrated that the hippocampus and cortical regions were affected in the mutant mice with an increase severity as the mice aged. In addition midbrain and cerebellum were found to be partly affected in mutant mice [87].

Trushina et al. studied the mitochondrial dynamics and function (motility, distribution, ultrastructure, etc) in neurons and brain tissue of three transgenic mice models expressing mutant human APP (Tg2576), PS1 (M146L mice) and the double mutation APP/PS1 [111]. Once mitochondrial trafficking, distribution, morphology and function were demonstrated to be affected in brain tissue from all three transgenic mice prior to the onset of cognitive decline, a metabolic profiling of brain tissue was carried out. GC-MS combined with multivariate statistical analysis by means of PLS-DA showed different gender related metabolic profiles leading to the comparison exclusively of females of all types of mice (three transgenic and one control mice). As a result, significant alterations in the levels of metabolites involved in energy metabolism including nucleotide metabolism, mitochondrial Krebs cycle, energy transfer, carbohydrate, neurotransmitter and amino acid metabolic pathways, were observed to be linked to familial AD [111] (Fig. 6).

As stated in the previous section, a tight link between AD and lipid metabolism has been already described. Namely, high dietary cholesterol has been suggested to accelerate 
pathologies related to $A \beta$ deposition [146] and furthermore, cellular cholesterol facilitates $A \beta$ generation in vitro and in vivo [147,148]. In a recent study, Wisniewski et al. [78] focused on the investigation of cholesterol metabolism in 19 post-mortem human BT (9 AD patients and 10 control subjects). Due to the low polarity of the metabolites involved in cholesterol pathways, a chloroform based solvent was used to extract the metabolites from BT samples. After sample analysis by HPLC-MS and confirmation by NMR, the proportion of desmosterol (a precursor of cholesterol) was found to be decreased in AD patients compared to age-matched controls. In another study, different metabolites related to lipid metabolism were observed to be altered in the progression to AD [75]. Samples under study included different post-mortem brain regions from 22 subjects, who at the time of death, had a clinical dementia rating score (from Morris [149]) of 0 (no dementia, $n=5$ ), 0.5 (very mild dementia, $n=3$ ), 1 (mild dementia, $n=4$ ), 2 (moderate dementia, $n=6$ ), or 3 (severe dementia, $n=4$ ). Lipid extracts were analyzed by a direct infusion ESI/MS in the negative ion mode. Sulfatides, a class of sulfated galactocerebrosides, decreased up to $58 \%$ in white matter and were found to be depleted up to $93 \%$ in gray matter at the earliest clinical stage of $\mathrm{AD}$ (0.5 dementia score). Authors surmised sulfatide deficiency as the earliest clinical stage of AD suggesting that its deficiency in AD may begin prior to the appearance of clinical symptoms [75].

\section{CONCLUSIONS AND FUTURE RESEARCH}

In this chapter, metabolomics approaches applied to $\mathrm{AD}$ investigation have been presented. It can be observed that Metabolomics has become an important tool in the discovery of new diagnostic and prognostic AD biomarkers in different samples. Up to date, human CSF has been the preferred biofluid for the investigation of $\mathrm{AD}$ metabolic biomarkers as it can closely reflect brain specific changes. However, there is a clear trend toward the use of less invasive sample analysis. Research on the metabolites exchange through the blood brain barrier and correlation in metabolic concentration between CSF and blood represent a challenge for future metabolomics studies.

To date, the frame in the discovery phase, within the global biomarker finding process, is the common aspect of all metabolomics works linked to AD. Thus most of metabolomics studies have been focused in the search of new biomarker candidates in the apparition and development of $\mathrm{AD}$ with high impact on novel hypotheses generation. Currently, to move forward, there is a growing need to reliable validate those findings increasing the cohort of clinical patients, to measure and validate the potential of the revealed biomarkers. 
Of particular importance in $\mathrm{AD}$ investigation is the discovery of biomarkers expressed before clinical symptoms appear. Pre-symptomatic events research represents an approach of special relevance in $\mathrm{AD}$ research for the potential impact on early therapy and disease progression understanding. Metabolomics works shown in this chapter have proven how the comparison of different metabolic fingerprints and metabolic profiles procurement from different phenotypes (health, MCI, AD) can be used to detect specific metabolic changes, potential biomarkers and altered metabolic pathways leading to the understanding of disease progression. Deepening in the mechanisms of disease will provide a source of potential new biomarkers helpful for early diagnosis, prognosis, prediction of response to therapy and disease progression. 


\section{REFERENCES}

[1] D.J. Selkoe, Physiol Rev., 81: 741-766, 2001

[2] K. Blennow, M.J. de Leon and H. Zetterberg, Lancet, 368: 387-403, 2006

[3] A. Wimo, C.C. Reed, R. Dodel, M. Belger, R.W. Jones, M. Happich, J.M. Argimon, G. Bruno, D. Novick, B. Vellas and J.M. Haro, J Alzheimers Dis., 36: 385-99, 2013

[4] P.T. Francis, A.M. Palmer, M. Snape and G.K. Wilcock., J Neurol Neurosurg Psychiatr., 66: 137-147, 1999

[5] I. Grundke-Iqbal, K. Iqbal, Y.C. Tung, M. Quinlan, H.M. Wisniewski and L.I. Binder, Proc Natl Acad Sci USA., 83: 4913-4917, 1986

[6] J.T. Jarrett, E.P. Berger and P.T. Lansbury Jr., Biochemistry, 32: 4693-4697, 1993

[7] T. Suzuki, M. Oishi, D.R. Marshak, A.J. Czernik, A.C. Nairn and P. Greengard, EMBO J., 13: 1114-1122, 1994

[8] J. Carter and C.F. Lippa, Curr Mol Med., 1: 733-737, 2001

[9] H. Kadowaki, H. Nishitoh, F. Urano, C. Sadamitsu, A. Matsuzawa, K. Takeda, H. Masutani, J. Yodoi, Y. Urano, T. Nagano and H. Ichijo, Cell Death Differ., 12: 19-24, 2005

[10] P. Calissano, C. Matrone and G. Amadoro, Commun Integr Biol., 2: 163-169, 2009

[11] K.A Welsh, N. Butters, J.P. Hughes, R.C. Mohs and A. Heyman, Arch. Neurol., 49: 448-452, 1992

[12] P.J. Nestor, P. Scheltens and J.R. Hodges, Nat Med., 10: S34-S41, 2004

[13] C. DeCarli, Lancet Neurol., 2: 15-21, 2003

[14] R.C. Petersen, J Intern Med., 256: 183-194, 2004

[15] R.C. Petersen, G.E. Smith, S.C. Waring, R.J. Ivnik, E.G. Tangalos and E. Kokmen, Arch Neurol., 56: 303-308, 1999

[16] K. Blennow and H. Hampel, Lancet Neurol., 2: 605-613, 2003

[17] A.F. Jorm, Gerontology, 46: 219-227, 2000 
[18] R.M. Sapolsky (Ed.) Stress, the aging brain, and the mechanisms of neuron death, MIT Press, Cambridge, 1992

[19] M. Reding, J. Haycox and J. Blass, Arch Neurol., 42: 894-896, 1985

[20] J. Guarch, T. Marcos, M. Salamero and R. Blesa, Int J Geriatr Psychiatry, 19: 352-358, 2004

[21] C.A. De Jager, E. Hogervorst, M. Combrinck and M.M. Budge, Psychol Med., 33: 1039-1050, 2003

[22] L. deToledo-Morrell, T.R. Stoub, M. Bulgakova, R.S. Wilson, D.A. Bennett, S. Leurgans, J. Wuu and D.A. Turner, Neurobiol Aging, 25: 1197-1203, 2004

[23] C.R. Jack Jr, M.M. Shiung, J.L. Gunter, P.C. O'Brien, S.D. Weigand, D.S. Knopman, B.F. Boeve, R.J. Ivnik, G.E. Smith, R.H. Cha, E.G. Tangalos and R.C. Petersen, Neurology, 62: 591600,2003

[24] H. Arai, T. Nakagawa, Y. Kosaka, M. Higuchi, T. Matsui, N. Okamura, M. Tashiro and H. Sasaki, Alzheimer Dis. Assoc. Disord., 3: 211-213, 1997

[25] K. Buerger, S.J. Teipel, R. Zinkoiwski, K. Blennow, H. Arai, R. Engel, K. Hofmann-Kiefer, C. McCulloch, U. Ptok, R. Heun, N. Andreasen, J. DeBernardis, D. Kerkman, H. Moeller, P. Davies and H. Hampel, Neurology, 59: 627-629, 2002

[26] N. Okamura, H. Arai, M. Maruyama, M. Higuchi, T. Matsui, H. Tanji, T. Seki, H. Hirai, H. Chiba, M. Itoh and H. Sasaki, Am J Psychiatry, 159: 474-476, 2002

[27] G. Fakhri El, M.F. Kijewski, K.A. Johnson, G. Syrkin, R.J. Killiany, J.A. Becker, R.E. Zimmerman and M.S. Albert, Arch Neurol., 60: 1066-1072, 2003

[28] R.A. Sperling, P.S. Aisen, L.A. Beckett, D.A. Bennett, S. Craft, A.M. Fagan, T. Iwatsubo, C.R. Jack Jr, J. Kaye, T.J. Montine, D.C. Park, E.M. Reiman, C.C. Rowe, E. Siemers, Y. Stern, K. Yaffe, M.C. Carrillo, B. Thies, M. Morrison-Bogorad, M.V. Wagster and C.H. Phelps, Alzheimers Dement., 7: 280-292, 2011

[29] J.C. Morris, Alzheimer Dis Assoc Disord., 19: 163-165, 2005

[30] G. McKhann, D. Drachman, M. Folstein, R. Katzman, D. Price and E.M. Stadlan, Neurology 34: 939-944, 1984 
[31] P. Tiraboschi, L.A. Hansen, L.J. Thal and J. Corey-Bloom, Neurology, 62: 1984-1989, 2004

[32] A. Anoop, P.K. Singh, R.S. Jacob and S.K. Maji, Int J Alzheimer Dis., 2010: 606802, 2010

[33] M. Shi, W.M. Caudle and J. Zhang, Neurobiology Dis., 35: 157-164, 2009

[34] S. Lista, F. Faltraco, D. Prvulovic and H. Hampel, Prog Neurobiol., 101-102: 1-17, 2013

[35] A. Cedazo-Minguez and B. Winblad, Exp Gerontol., 45: 5-14, 2010

[36] J. Birks and R.J. Harvey, Cochrane Database Syst Rev., 25: CD001190, 2006

[37] H. Kaduszkiewicz, T. Zimmermann, H.P. Beck-Bornholdt and H. van den Bussche, BMJ., 331 :321-327, 2005

[38] T. Dwolatzky and A.M. Clarfield, Aging Health, 8: 233-237, 2012

[39] S. Gauthier and J.L. Molinuevo, Alzheimers Dement., 9: 326-331, 2013

[40] P.N. Tariot, M.R. Farlow, G.T. Grossberg, S.M. Graham, S. McDonald and I. Gergel, JAMA, 291: $317-24,2004$

[41] J. Choi and E.W. Twamley, Neuropsychol Rev., 23: 48-62, 2013

[42] V. Buschert, A.L.W. Bokde and H. Hampel, Nat Rev Neurol., 6: 508-517, 2010

[43] M.S. Chong and S. Sahadevan, Lancet Neurol., 4: 576-579, 2005

[44] E. Portelius, H. Zetterberg, J. Gobom, U. Andreasson and K. Blennow, Expert Rev Proteomics, 5: $225-237,2008$

[45] H. Zetterberg, K. Blennow and E. Hanse, Exp Gerontol., 45: 23-29, 2010

[46] H. Zetterberg, Scand J Clin Lab Invest., 69: 18-21, 2009

[47] M. Shi, Y.T. Sui, E.R. Peskind, G. Li, H. Hwang, I. Devic, C. Ginghina, J.S. Edgar, C. Pan, D.R. Goodlett, A.R. Furay, L.F. Gonzalez-Cuyar and J. Zhang, J Alzheimers Dis., 27: 299-305, 2011

[48] J.E. Meredith Jr, S. Sankaranarayanan, V. Guss, A.J. Lanzetti, F. Berisha, R.J. Neely, J.R. Slemmon, E. Portelius, H. Zetterberg, K. Blennow, H. Soares, M. Ahlijanian and C.F. Albright, PLoS One, 8: e76523, 2013 
[49] Z. Zhong, M. Ewers, S. Teipel, K. Burger, A. Wallin, K. Blennow, P. He, C. McAllister, H. Hampel and Y. Shen, Arch Gen Psychiatry, 8: 718-726, 2007

[50] H. Zetterberg, U. Andreasson, O. Hansson, G. Wu, S. Sankaranarayanan, M.E. Andersson, P. Buchhave, E. Londos, R.M. Umek, L. Minthon, A.J. Simon and K. Blennow, Arch Neurol., 8: 1102-1107, 2008

[51] J. Raber, Y. Huang and J.W. Ashford, Neurobiol Aging, 25: 641-650, 2004

[52] Z.S. Tan, S. Seshadri, A. Beiser, P.W. Wilson, D.P. Kiel, M. Tocco, R.B. D'Agostino and P.A. Wolf, Arch Intern Med. 163: 1053-1057, 2003

[53] R.M. Evans, C.L. Emsley, S. Gao, A. Sahota, K.S. Hall, M.R. Farlow and H. Hendrie, Neurology, 54: 240-242, 2000

[54] S. Seshadri, A. Beiser, J. Selhub, P.F. Jacques, I.H. Rosenberg, R.B. D'Agostino, P.W. Wilson and P.A. Wolf, N Engl J Med., 346: 476-483, 2002

[55] R. Ghidoni, L. Benussi, A. Paterlini, V. Albertini, G. Binetti and E. Emanuele, Neurodegener Dis., 8: 413-420, 2011

[56] V. Ozdemir, G. Suarez-Kurtz, R. Stenne, A.A. Somogyi, S.O. Kayaalp and E. Kolker, OMICS 13: 43-62, 2009

[57] G.T. Sutherland, M. Janitz and J.J. Kril, J Neurochem., 116: 937-946, 2011.

[58] X.H. Xu, Y. Huang, G. Wang and S.D. Chen, Neurosci Bull., 28: 641-648, 2012.

[59] I. Barba, R. Fernandez-Montesinos, D. Garcia-Dorado and D. Pozo, J Cell Mol Med., 12: $1477-1485,2008$

[60] C. Ibañez, C. Simo and A. Cifuentes, Electrophoresis, 34: 2799-2811, 2013

[61] E. Trushina and M.M. Mielke, Biochim Biophys Acta., in press, doi: 10.1016/j.bbadis.2013.06.014, 2013

[62] T. Dunckley, K.D. Coon and D.A. Stephan, Drug Discov Today., 10: 326-334, 2005

[63] C. Bazenet and S. Lovestone, Biomark Med., 6: 441-454, 2012

[64] O. Fiehn, Comp Funct Genomics, 2: 155-168, 2001 
[65] X. Zhang, D. Wei, Y. Yap, L. Li, S. Guo and F. Chen, Mass Spectrom Rev., 26: 403-431, 2007

[66] M. Oresic, A. Vidal-Puig and V. Hänninen, Expert Rev Mol Diagn., 6: 575-585, 2006

[67] G. Hassan-Smith, G.R. Wallace, M.R. Douglas and A.J. Sinclair, J Neuroimmunol., 248: 4852,2012

[68] J. Hardy and D.J. Selkoe, Science, 297: 353-356, 2002

[69] J. Povova, P. Ambroz, M. Bar, V. Pavukova, O. Sery, H. Tomaskova and V. Janout, Biomed Pap., 156: 108-114, 2012

[70] M.C. Irizarry, NeuroRx., 1: 226-234, 2004

[71] W.B. Dunn and D.I. Ellis, Trends Anal Chem., 24: 285-293, 2005

[72] S. Zhang, G.A. Nagana-Gowda, T. Ye and D. Raftery, Analyst, 135: 1490-1498, 2010

[73] B. Zhang and R. Powers, Future Med Chem., 4: 1273-1306, 2012

[74] F.Y. Ghauri, J.K. Nicholson, B.C. Sweatman, J. Wood, C.R. Beddell, J.C. Lindon and N.J. Cairns, NMR Biomed., 6: 163-167, 1993

[75] X. Han, D.M. Holtzman, D.W. McKeel Jr, J. Kelley and J.C. Morris, J Neurochem., 82: 809818,2002

[76] F. Nicoli, J. VionDury, S. ConfortGouny, S. Maillet, J.L. Gastaut and P.J. Cozzone, C R Acad Sci III., 319: 623-631, 1996

[77] T. Tukiainen, T. Tynkkynen, V.P. Mäkinen, P. Jylänki, A. Kangas, J. Hokkanen, A. Vehtari, O. Gröhn, M. Hallikainen, H. Soininen, M. Kivipelto, P.H. Groop, K. Kaski, R. Laatikainen, P. Soininen, T. Pirttilä and M. Ala-Korpela, Biochem Biophys Res Commun., 375: 356-361, 2008

[78] T. Wisniewski, K. Newman and N.B. Javitt, J Alzheimers Dis., 33: 881-888, 2013

[79] Z. Lei, D.V. Huhman and L.W. Sumner, J Biol Chem., 286: 25435-25442, 2011

[80] K. Dettmer, P.A. Aronov and B.D. Hammock, Mass Spectrom Rev., 26: 51-78, 2007

[81] G.A. Barding Jr, R. Salditos and C.K. Larive, Anal Bioanal Chem., 404: 1165-1179, 2012

[82] A. Smolinska, L. Blanchet, L.M. Buydens and S.S. Wijmenga, Anal Chim Acta, 750: 82-97, 2012 
[83] O. Fiehn, Plant Mol Biol., 48: 155-171, 2002

[84] D.B. Kell, M. Brown, H.M. Davey, W.B. Dunn, I. Spasic and S.G. Oliver, Nat Rev Microbiol., 3: $557-565,2005$

[85] D.I. Ellis, W.B. Dunn, J.L. Griffin, J.W. Allwood and R. Goodacre, Pharmacogenomics, 8: 1243-1266, 2007

[86] M.G. Barderas, C.M. Laborde, M. Posada, F. de la Cuesta, I. Zubiri, F. Vivanco and G. Alvarez-Llamas, J Biomed Biotechnol., 2011: 790132, 2011

[87] R.M. Salek, J. Xia, A. Innes, B.C. Sweatman, R. Adalbert, S. Randle, E. McGowan, P.C. Emson and J.L. Griffin, Neurochem Int., 56: 937-947, 2010

[88] E.P. Botosoa, M. Zhu, C. Marbeuf-Gueye, M.N. Triba, F. Dutheil, C. Duyckäerts, P. Beaune, M.A. Loriotb and L. Le Moyec, IRBM, 33: 281-286, 2012

[89] K. Fukuhara, A. Ohno, Y. Ota, Y. Senoo, K. Maekawa, H. Okuda, M. Kurihara, A. Okuno, S. Niida, Y. Saito and O. Takikawa, J Clin Biochem Nutr., 52: 133-138, 2013

[90] N.M. Jukarainen, S.P. Korhonen, M.P. Laakso, M.A. Korolainen, M. Niemitz, P.P. Soininen, K. Tuppurainen, J. Vepsäläinen, T. Pirttila and R. Laatikainen, Metabolomics, 4: 150-160, 2008

[91] N.J. Li, W.T. Liu, W. Li, S.Q. Li, X.H. Chen, K.S. Bi and P. He, Clin Biochem., 43: 992-997, 2010

[92] C. Czech, P. Berndt, K. Busch, O. Schmitz, J. Wiemer, V. Most, H. Hampel, J. Kastler and H. Senn, PloS One, 7: e31501, 2012

[93] C. Ibañez, C. Simo, P.J. Martín-Álvarez, M. Kivipelto, B. Winblad, A. Cedazo-Mínguez and A. Cifuentes, Anal Chem., 84: 8532-8540, 2012

[94] S.F. Graham, O.P. Chevallier, D. Roberts, C. Hölscher, C.T. Elliott and B.D. Green, Anal Chem., 85: 1803-1811, 2013

[95] K. Dettmer and B.D. Hammock, Environ Health Perspect., 112: A396-A397, 2004

[96] A. Luedemann, L. von Malotky, A. Erban and J. Kopka, Methods Mol Biol., 860: 255-286, 2012 
[97] K. Inoue, H. Tsutsui, H. Akatsu, Y. Hashizume, N. Matsukawa, T. Yamamoto and T. Toyo'oka, Sci Rep., 3: 2364, 2013

[98] A.N. Fonteh, R.J. Harrington, A. Tsai, P. Liao and M.G. Harrington, Amino Acids, 32: 213224,2007

[99] S. Roche, A. Gabelle and S. Lehman, Proteomics Clin Appl., 2: 428-436, 2008

[100] M. Ramström, A. Zuberovic, C. Grönwall, J. Hanrieder, J. Bergquist and S. Hober, Biotechnol Appl Biochem., 52: 159-66, 2009

[101] R. Kaddurah-Daouk, S. Rozen, W. Matson, X. Han, C.M. Hulette, J.R. Burke, P.M. Doraiswamy and K.A. Welsh-Bohmer, Alzheimers Dement., 7: 309-317, 2011

[102] S. Samakashvili, C. Ibañez, C. Simo, F.J. Gil-Bea, B. Winblad, A. Cedazo-Mínguez and A. Cifuentes, Electrophoresis, 32: 2757-2764, 2011

[103] C. Ibañez, C. Simo, D.K. Barupal, O. Fiehn, M. Kivipelto, A. Cedazo-Mínguez and A. Cifuentes, J Chromatogr A, 1302: 65-71, 2013

[104] C. Simo, C. Ibañez, A. Gómez-Martínez, J.A. Ferragut and A. Cifuentes, Electrophoresis, 32: 765-1777, 2011

[105] K.T. Myint, K. Aoshima, S. Tanaka, T. Nakamura and Y. Oda, Anal Chem., 81: 1121-1129, 2009

[106] C. Advokat and A.I. Pellegrin, Neurosci Biobehav Rev., 16: 13-24, 1992

[107] C.R. Jack Jr, D.S. Knopman, W.J. Jagust, L.M. Shaw, P.S. Aisen, M.W. Weiner, R.C. Petersen and J.Q. Trojanowski, Lancet Neurol., 9: 119-128, 2010.

[108] R. Kaddurah-Daouk, H. Zhu, S. Sharma, M. Bogdanov, S.G. Rozen, W. Matson, N.O. Oki, A.A. Motsinger-Reif, E. Churchill, Z. Lei, D. Appleby, M.A. Kling, J.Q. Trojanowski, P.M. Doraiswamy and S.E. Arnold, Transl Psychiatry, 3: e244, 2013

[109] A.A. Motsinger-Reif, H. Zhu, M.A. Kling, W. Matson, S. Sharma, O. Fiehn, D.M. Reif, D.H. Appleby, P.M. Doraiswamy, J.Q. Trojanowski, R. Kaddurah-Daouk and S.E. Arnold, Acta Neuropathol Commun., 1: 28, 2013

[110] G. Perry, A.D. Cash and M.A. Smith, J Biomed Biotechnol., 2: 120-123, 2002 
[111] E. Trushina, E. Nemutlu, S. Zhang, T. Christensen, J. Camp, J. Mesa, A. Siddiqui, Y. Tamura, H. Sesaki, T.M. Wengenack, P.P. Dzeja and J.F. Poduslo, PLoS One, 7: e32737, 2012

[112] M. Pohanka, Curr Med Chem., 21: 356-364, 2013

[113] K. Jomova, D. Vondrakova, M. Lawson and M. Valko, Mol Cell Biochem., 345: 91-104, 2010

[114] D.A. Butterfield, Free Radic Res., 36: 1307-1313, 2002

[115] D.G. Smith, R. Cappai and K.J. Barnham, Biochim Biophys Acta, 1768: 1976-1990, 2007

[116] L.P. Wang and J.F. Schmidt, Dan Med Bull., 44: 79-81, 1997

[117] R.W. Evans, Neurol Clin., 16: 83-105, 1998

[118] J.M. Boon, P.H. Abrahams, J.H. Meiring and T. Welch, Clin Anat., 17: 544-553, 2004

[119] M.F. Aftab and R.S. Waraich, Am J Neurosci., 3: 54-62, 2012

[120] A. Hye, S. Lynham, M. Thambisetty, M. Causevic, J. Campbell, H.L. Byers, C. Hooper, F. Rijsdijk, S.J. Tabrizi, S. Banner, C.E. Shaw, C. Foy, M. Poppe, N. Archer, G. Hamilton, J. Powell, R.G. Brown, P. Sham, M. Ward and S. Lovestone, Brain, 129: 3042-3050, 2006

[121] C. Humpel and T. Hochstrasser, World J Psychiatr., 1: 8-18, 2011

[122] K. Blennow, H. Hampel, M. Weiner and H. Zetterberg, Nat Rev Neurol., 6: 131-144, 2010

[123] E. Trushina, T. Dutta, X.M. Persson, M.M. Mielke and R.C. Petersen, PLoS One, 8: e63644, 2013

[124] M. Oresic, T. Hyötyläinen, S.K. Herukka, M. Sysi-Aho, I. Mattila, T. Seppänan-Laakso, V. Julkunen, P.V. Gopalacharyulu, M. Hallikainen, J. Koikkalainen, M. Kivipelto, S. Helisalmi, J. Lötjönen and H. Soininen, Transl Psychiatry, 1: e57, 2011

[125] P. Foley, Biochim Biophys Acta, 1801: 750-753, 2010

[126] E.H. Corder, A.M. Saunders, W.J. Strittmatter, D.E. Schmechel, P.C. Gaskell, G.W. Small, A.D. Roses, J.L. Haines and M.A. Pericak-Vance, Science, 261: 921-923, 1993

[127] L. Bertram and R.E. Tanzi, Nature Rev Neurosci., 9: 768-778, 2008

[128] J. Kim, J.M. Basak and D.M. Holtzman, Neuron, 63: 287-303, 2009 
[129] T. Hartmann, J. Kuchenbecker and M.O. Grimm, J Neurochem., 103: 159-170, 2007

[130] F.G. Sagin and E.Y. Sozmen, Curr Alzheimer Res., 5: 4-14, 2008

[131] N. Greenberg, A. Grassano, M. Thambisetty, S. Lovestone and C. Legido-Quigley, Electrophoresis, 30: 1235-1239, 2009

[132] Y. Sato, T. Nakamura, K. Aoshima and Y. Oda, Anal Chem., 82: 9858-9864, 2010

[133] X. Han, S. Rozen, S.H. Boyle, C. Hellegers, H. Cheng, J.R. Burke, K.A. Welsh-Bohmer, P.M. Doraiswamy and R. Kaddurah-Daouk, PLoS One, 6: e21643, 2011

[134] D.L. Sparks, M.N. Sabbagh, D.J. Connor, J. Lopez, L.J. Launer, P. Browne, D. Wasser, S. Johnson-Traver, J. Lochhead and C. Ziolwolski, Arch Neurol., 62: 753-757, 2005

[135] J.D. Buxbaum, E.I. Cullen and L.T. Friedhoff, Front Biosci., 7: a50-a59, 2002

[136] M. Simons, F. Schwärzler, D. Lütjohann, K. von Bergmann, K. Beyreuther, J. Dichgans, H. Wormstall, T. Hartmann and J.B. Schulz, Ann Neurol., 52: 346-350, 2002

[137] S. Grosgen, M.O. Grimm, P. Friess and T. Hartmann, Biochim Biophys Acta, 1801: 966-974, 2010

[138] C.F. Sing and J. Davignon, Am J Hum Genet., 37: 268-285, 1985

[139] Y. Sato, I. Suzuki, T. Nakamura, F. Bernier, K. Aoshima and Y. Oda, J Lipid Res., 53: 567576,2012

[140] T.G. Beach, J Alzheimers Dis., 33: S219-S233, 2013

[141] M.A. Chishti, D.S. Yang, C. Janus, A.L. Phinney, P. Horne, J. Pearson, R. Strome, N. Zuker, J. Loukides, J. French, S. Turner, G. Lozza, M. Grilli, S. Kunicki, C. Morissette, J. Paquette, F. Gervais, C. Bergeron, P.E. Fraser, G.A. Carlson, P.S. George-Hyslop and D. Westaway, J Biol Chem., 276: 21562-21570, 2001

[142] D. Games, D. Adams, R. Alessandrini, R. Barbour, P. Berthelette, C. Blackwell, T. Carr, J. Clemens, T. Donaldson, F. Gillespie, T. Guido, S. Hagopian, K. Johnsonwood, K. Khan, M. Lee, P. Leibowitz, I. Lieberburg, S. Little, E. Masliah, L. McConlogue, M. Montoyazavala, L. Mucke, L. Paganini, E. Penniman, M. Power, D. Schenk, P. Seubert, B. Snyder, F. Soriano, H. Tan, J. Vitale, S. Wadsworth, B. Wolozin and J. Zhao, Nature, 373: 523-527, 1995 
[143] K. Hsiao, P. Chapman, S. Nilsen, C. Eckman, Y. Harigaya, S. Younkin, F. Yang and G. Cole, Science, 274: 99-102, 1996

[144] C. Janus, A.L. Phinney, M.A. Chishti and D. Westaway, Curr Neurol Neurosci Rep., 1: 451457, 2001

[145] L. Mucke, E. Masliah, G.Q. Yu, M. Mallory, E.M. Rockenstein, G. Tatsuno, K. Hu, D. Kholodenko, K. Johnson-Wood and L. McConlogue, J Neurosci., 20: 4050-4058, 2000

[146] L.M. Refolo, B. Malester, J. LaFrancois, T. Bryant-Thomas, R. Wang, G.S. Tint, K. Sambamurti, K. Duff and M.A. Pappolla, Neurobiol Dis., 7: 321-331, 2000

[147] M. Simons, P. Keller, B. De Strooper, K. Beyreuther, C.G. Dotti and K. Simons, Proc Natl Acad Sci USA., 95: 6460-6464, 1998

[148] E.R. Frears, D.J. Stephens, C.E. Walters, H. Davies and B.M. Austen, Neuroreport., 10: 16991705,1999

[149] J.C. Morris, Neurology, 43: 2412-2414, 1993

[150] M.O. Grimm, S. Grösgen, M. Riemenschneider, H. Tanila, H.S. Grimm and T. Hartmann, J Chromatogr A, 1218: 7713-7722, 2011 


\section{FIGURES}

Figure 1. Graphic representation of the proposed staging framework for preclinical AD. Note that some individuals will not progress beyond Stage 1 or Stage 2. Individuals in Stage 3 are postulated to be more likely to progress to MCI and AD dementia. Abbreviations: AD, Alzheimer's disease; $\mathrm{A} \beta$, amyloid beta; PET, position emission tomography; CSF, cerebrospinal fluid; FDG, fluorodeoxyglucose, fMRI, functional magnetic resonance imaging, sMRI, structural magnetic resonance imaging. (Reproduced from [28]).

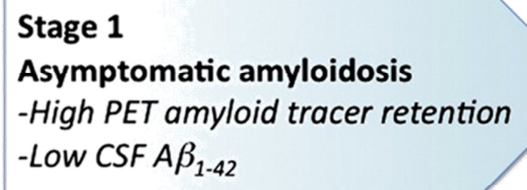

\section{Stage 3}

Amyloidosis + Neurodegeneration + Subtle Cognitive Decline

-Evidence of subtle change from baseline level of cognition

-Poor performance on more challenging cognitive tests

-Does not yet meet criteria for $\mathrm{MCl}$ 
Figure 2. Determination of analytes contributing significantly to separation between AD patients and healthy controls by O-PLSDA of the CSF data set. (A) OPLS-DA score plot for light AD patients (MMSE.22) vs. controls. (B) OPLS-DA coefficient plot for light AD patients (MMSE.22) vs. controls. Cysteine and uridine are the most relevant analytes for separating light AD patients (MMSE.22) from healthy subjects. (Reproduced from [92]).
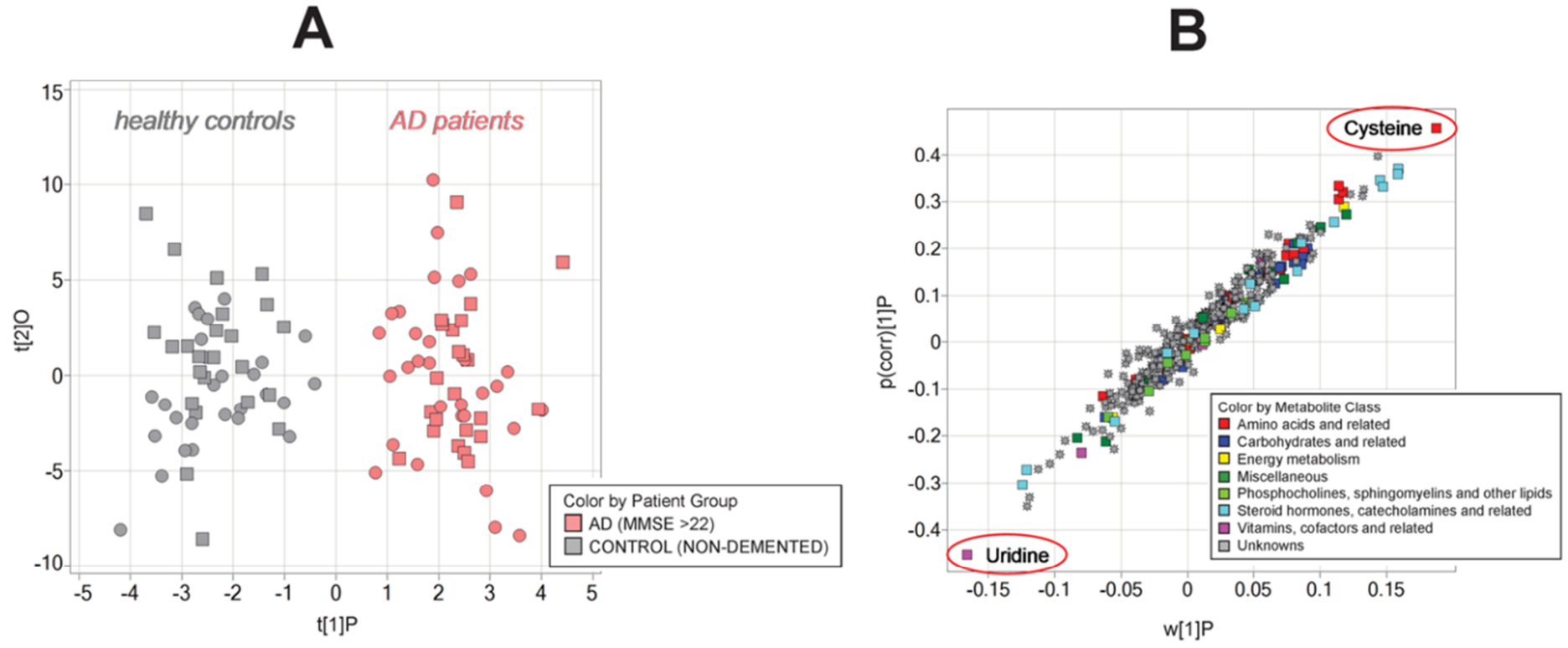
Figure 3. Changes in free amino acid (FAA) and dipeptide (DP) concentrations in AD samples. After LC/MS ${ }^{2}$ analysis, mole quantities (nmol=dl) of FAAs and DPs in samples from subjects without or with AD were calculated. Then the change in the mean concentration of FAA and DPs in $\mathrm{AD}(\mathrm{n}=8)$ compared to healthy controls $(\mathrm{n}=8)$ was achieved and expressed as the $\%$ change in $\mathrm{AD}$ compared to controls $(* \mathrm{p}<0.05)$. (Modified from [98]).

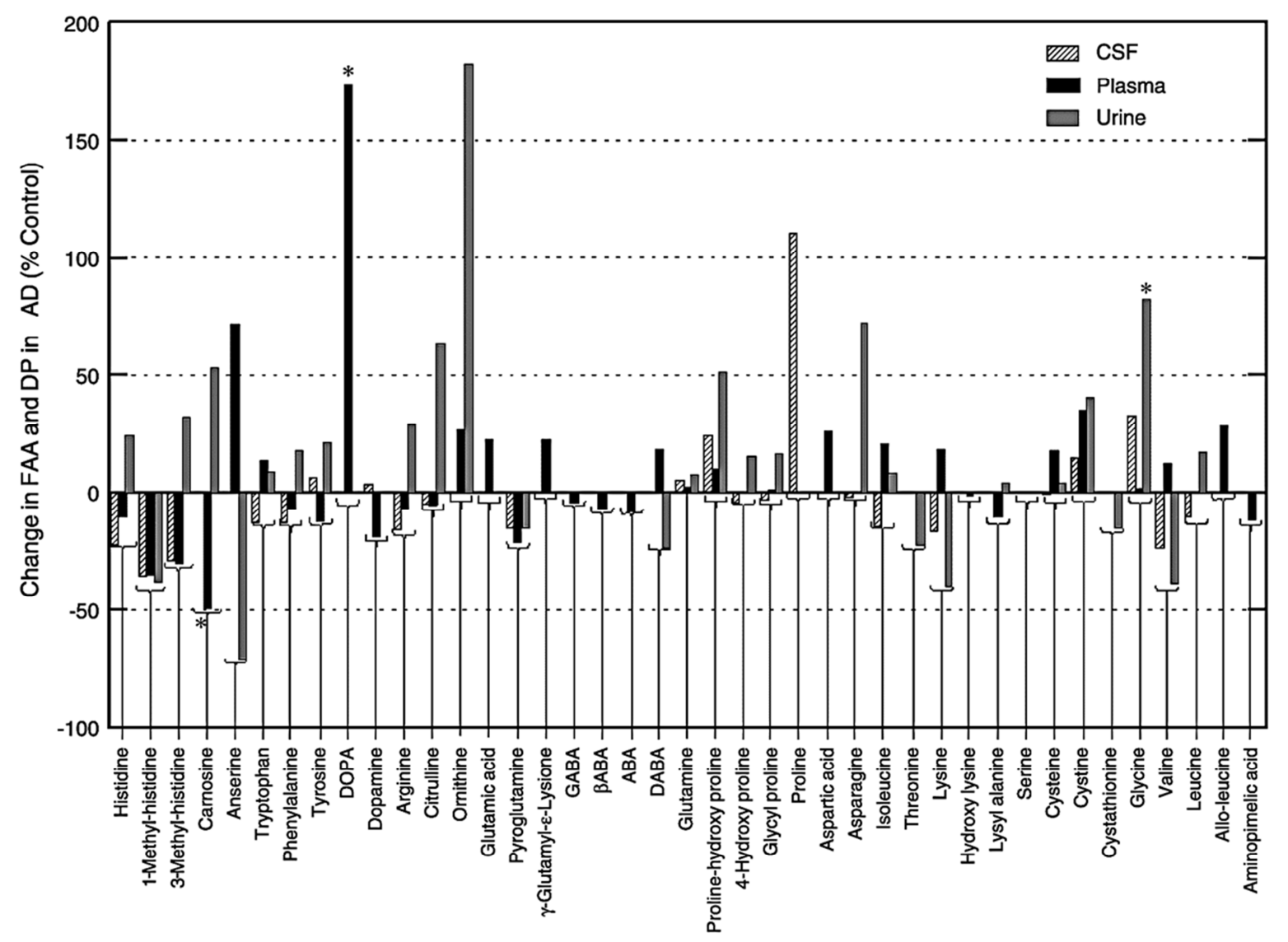


Figure 4. Metabolic pathway of polyamines. Increased levels of spermidine, spermine, putrescine, acetylspermidine and acetylspermine without a change of ornithine in AD pathology were observed. One theory suggests that the NMDA receptor excitotoxicity is caused by an excess of spermidine and spermine due to ornithine decarboxylase activity induced by plaque and/or tangle deposition in specific brain regions. (Reproduced from [97]).

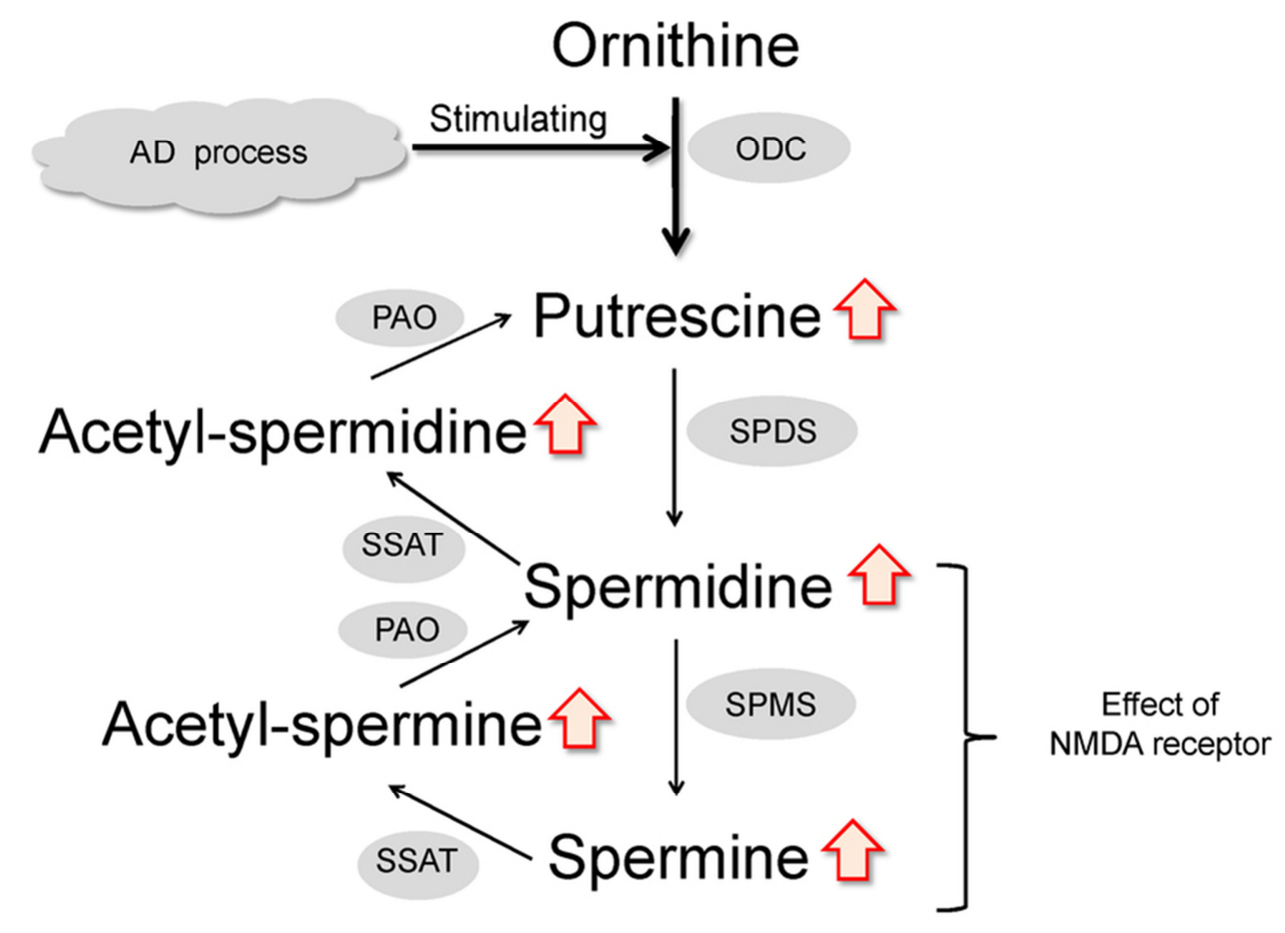


Figure 5. (A) UHPLC ESI+ chromatogram of the polar extract of post-mortem brain tissue. (B) The scores plot displaying the separation between the two sample groups ( $\mathrm{AD}=$ blue; controls $=$ red). Explained variance (R2) was $97 \%$, predictive ability (Q2) was $93 \%$, and root-mean-square error of validation (RMSEV) was 15\%. (C) The loadings plots which correspond to the scores in B. Indicated in blue $(\mathrm{n}=24)$ and red $(\mathrm{n}=17)$ are metabolites which significantly differ between groups (higher in $\mathrm{AD}$ and controls, respectively). These are further emphasized by the S-line-plot (D) and their relative variable importance to the model. (Reproduced from [94]).

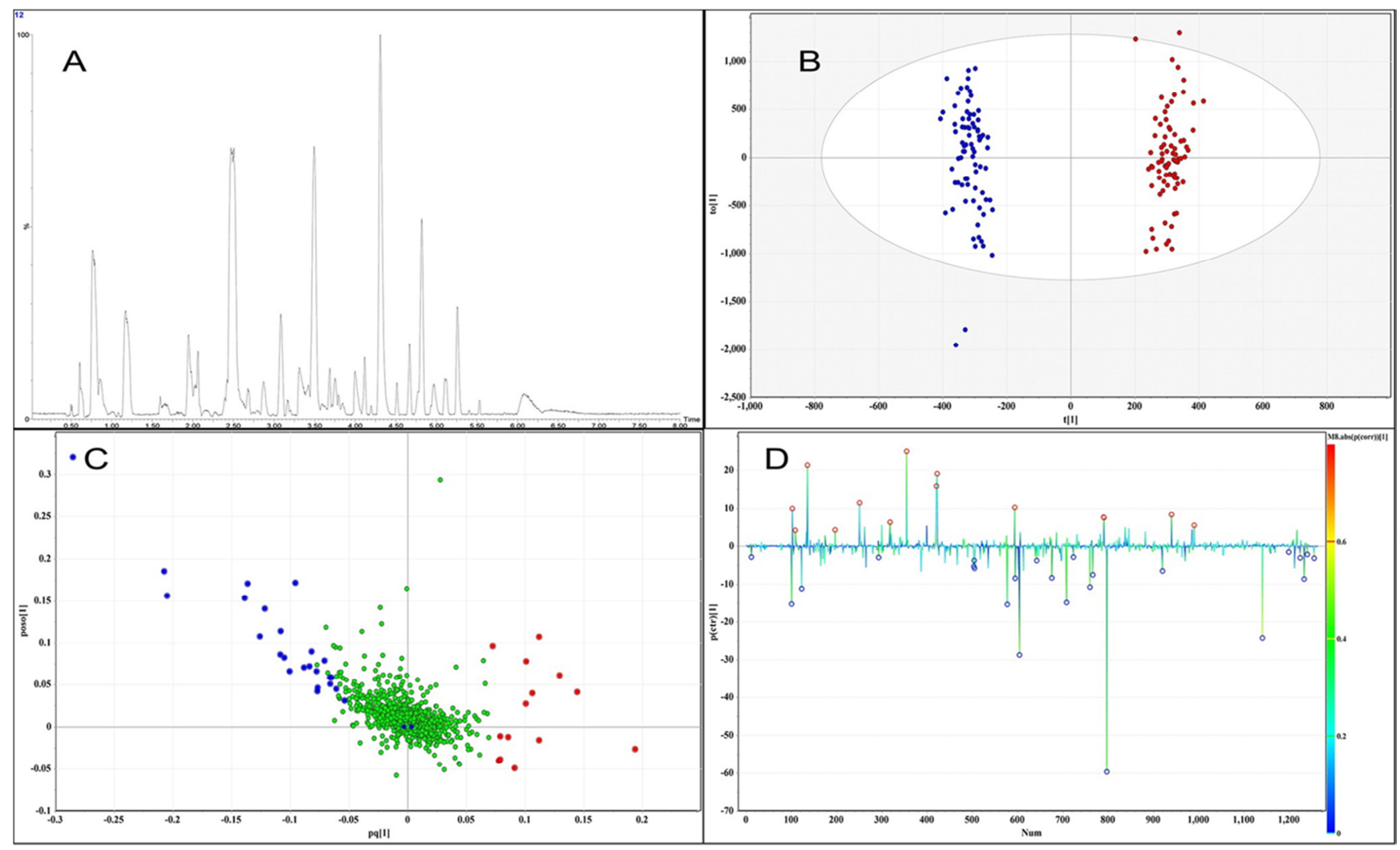


Figure 6. Comparison of individualized metabolomic profiles and affected metabolic pathways in FAD mouse models. A, B and C (left panels): PLS-DA score plots showing distinct metabolomic profiles of PS1 (A), APP (B) and APP/PS1 (C) female mutant mice (Tg)) compared to nontransgenic (NTG) littermates. A, B and C (central panels): Panels of specific biomarkers as a plot of variable importance in the projection (VIP) indicating the 15 most significant metabolites in discriminating between metabolomic profiles of NTG and Tg groups in the PLS-DA model. A, B and $\mathbf{C}$ (right panels): Metabolic pathways specifically affected in each FAD mouse model. (Reproduced from [111]).

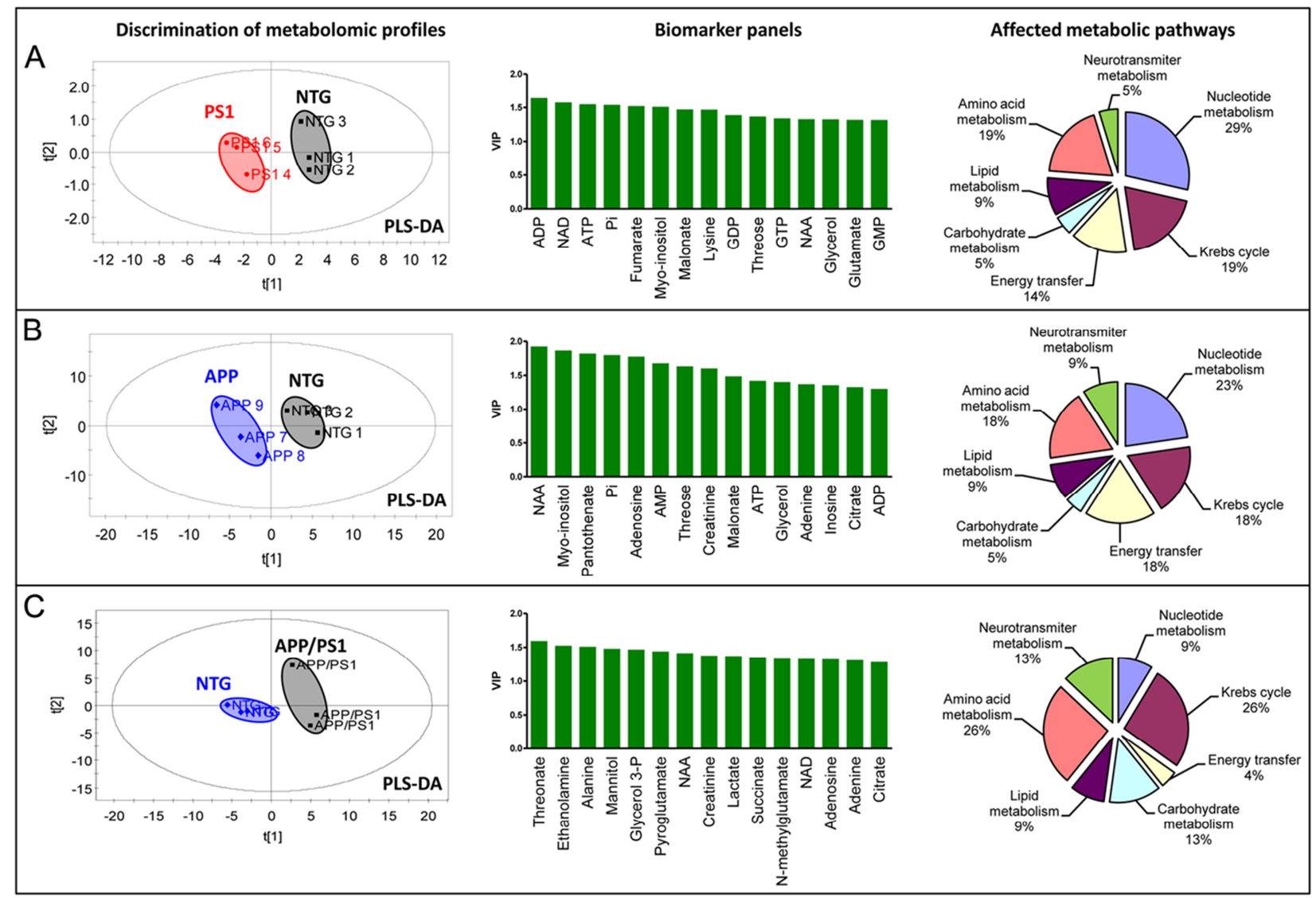


Table 1. Metabolomic applications in AD research.

\begin{tabular}{|c|c|c|c|c|}
\hline Sample & Groups of samples & Metabolomic approach & Analytical Platform & Ref. \\
\hline Post-mortem CSF & 23 samples from AD patients and healthy controls & $\begin{array}{l}\text { Metabolic profiling of } 2.4-2.9 \\
\text { NMR region }\end{array}$ & NMR & [74] \\
\hline Post-mortem human brain & $\begin{array}{l}\text { Subjects with no dementia }(n=5) \text {, very mild dementia }(n=3) \text {, mild dementia } \\
\qquad(n=4) \text {, moderate dementia }(n=6) \text { and severe dementia }(n=4)\end{array}$ & Lipid profiling & ESI-QqQ MS & [75] \\
\hline CSF & $\begin{array}{l}\text { Demented patients }(\mathrm{n}=12) \text {, healthy subjects }(\mathrm{n}=17) \text {, multiple sclerosis patients } \\
\qquad(\mathrm{n}=19)\end{array}$ & $\begin{array}{l}\text { Metabolic profiling of } \\
\text { oxidative metabolism }\end{array}$ & NMR & [76] \\
\hline Serum & MCI $(n=19)$ y control $(n=26)$ subjects. & Lipid profiling & NMR & [77] \\
\hline Post-mortem human brain & AD patients $(n=9)$ and control subjects $(n=10)$. & $\begin{array}{l}\text { Metabolic profiling of } \\
\text { cholesterol metabolism }\end{array}$ & $\begin{array}{l}\text { HPLC-Q/MS } \\
\text { NMR }\end{array}$ & [78] \\
\hline Post-mortem mice brain & $\begin{array}{l}8 \text { brain regions from young mice TgCRND8 }(n=5) \text { and control young mice } \\
(n=4) \text {, and aged mice TgCRND8 }(n=3) \text { and control old mice }(n=5) \text {. }\end{array}$ & Metabolic fingerprinting & NMR & [87] \\
\hline Post-mortem human brain & $\mathrm{AD}(\mathrm{n}=8)$ and $\mathrm{AML}(\mathrm{n}=11)$ patients. & Metabolic fingerprinting & NMR & [88] \\
\hline Rat urine & $\begin{array}{l}\text { Control }(n=4) \text { and transgenic APP/tau rats at three life-time points: } 4(n=4), 10 \\
\qquad(n=4) \text { and } 15(n=3) \text { months. }\end{array}$ & Metabolic fingerprinting & NMR & [89] \\
\hline CSF & $\begin{array}{l}\text { Healthy subjects with typical } \mathrm{AD} \text { biomarkers }(\mathrm{A} \beta \text { y tau })(\mathrm{n}=10) \text { and without } \\
\text { typical } \mathrm{AD} \text { biomarkers }(\mathrm{n}=34) .\end{array}$ & Metabolic fingerprinting & NMR & [90] \\
\hline Plasma & AD patients $(n=20)$, healthy subjects $(n=20)$ & Metabolic fingerprinting & UHPLC-QqQ/MS & [91] \\
\hline CSF & AD patients $(\mathrm{n}=79)$ and control subjects $(\mathrm{n}=51)$. & Metabolic fingerprinting & $\begin{array}{l}\text { GC-TOF MS } \\
\text { LC-MS/MS }\end{array}$ & [92] \\
\hline CSF & $\begin{array}{l}\mathrm{AD}(\mathrm{n}=23), \text { MCI with progression to } \mathrm{AD}(\mathrm{n}=9) \text {, MCI without progression to } \mathrm{AD} \\
\qquad(\mathrm{n}=22) \text { and control }(\mathrm{n}=19) \text { subjects. Validation set }(\mathrm{n}=12)\end{array}$ & Metabolic fingerprinting & CE-TOF MS & [93] \\
\hline Post-mortem human brain & AD patients $(n=15)$ and control subjects $(n=15)$. Validation set $(n=60)$. & Metabolic fingerprinting & UHPLC-Q/TOFMS & [94] \\
\hline
\end{tabular}




\begin{tabular}{|c|c|c|c|c|}
\hline CSF, Plasma, Urine & AD patients $(n=8)$, healthy subjects $(n=8)$ & $\begin{array}{l}\text { Metabolic profiling of amino } \\
\text { acids and dipeptides }\end{array}$ & HPLC-MS $^{2}$ & [98] \\
\hline Post-mortem CSF & AD patients $(n=15)$ and control subjects $(n=15)$. & Metabolic fingerprinting & HPLC-ECA & [101] \\
\hline CSF & $\begin{array}{l}4 \text { pool of samples from } A D(n=27), \text { MCI with progression to } A D(n=13), M C I \\
\text { without progression to } A D(n=26) \text { and control }(n=46) \text { subjects. }\end{array}$ & $\begin{array}{l}\text { Metabolic profiling of amino } \\
\text { acids }\end{array}$ & MEKC-LIF & [102] \\
\hline CSF & $\begin{array}{l}\mathrm{AD}(\mathrm{n}=21), \text { MCI with progression to } \mathrm{AD}(\mathrm{n}=12), \text { MCI without progression to } \\
\qquad \mathrm{AD}(\mathrm{n}=21) \text { and control }(\mathrm{n}=21) \text { subjects. }\end{array}$ & Metabolic fingerprinting & UHPLC-TOF MS & [103] \\
\hline CSF & AD patients $(n=18)$, healthy subjects $(n=18)$ & $\begin{array}{l}\text { Hydrophilic metabolites } \\
\text { profiling }\end{array}$ & nLC-Q/TOF MS & [105] \\
\hline CSF & $\mathrm{AD}(\mathrm{n}=40), \operatorname{MCI}(\mathrm{n}=36)$ and control $(\mathrm{n}=38)$ subjects. & Metabolic fingerprinting & HPLC-ECA & [108] \\
\hline CSF & AD patients $(n=40)$ and control subjects $(n=38)$. & Metabolic fingerprinting & $\begin{array}{l}\text { HPLC-ECA } \\
\text { GC-TOF MS }\end{array}$ & [109] \\
\hline Post-mortem mice brain & Control $(n=3)$ and transgenic (APP/PS1) $(n=3)$ mice. & $\begin{array}{l}\text { Metabolic profiling of energetic } \\
\text { metabolism }\end{array}$ & GC-TOF MS & [111] \\
\hline CSF and Plasma & $\mathrm{AD}(\mathrm{n}=15), \operatorname{MCI}(\mathrm{n}=10)$ and control $(\mathrm{n}=10)$ subjects. & Metabolic fingerprinting & UHPLC-TOF MS & [123] \\
\hline Serum & $\begin{array}{l}\mathrm{AD}(\mathrm{n}=37), \text { MCI with progression to } \mathrm{AD}(\mathrm{n}=52), \text { MCI without progression to } \\
\qquad \operatorname{AD}(\mathrm{n}=91) \text { and control }(\mathrm{n}=46) \text { subjects. }\end{array}$ & $\begin{array}{l}\text { Lipid profiling } \\
\text { Metabolic fingerprinting }\end{array}$ & $\begin{array}{c}\text { UHPLC-MS } \\
\text { GC x GC-TOF MS }\end{array}$ & [124] \\
\hline Plasma & $\mathrm{AD}(\mathrm{n}=16), \mathrm{MCI}(12)$ and control $(\mathrm{n}=10)$ subjects. & $\begin{array}{l}\text { Metabolic profiling of bile } \\
\text { acids }\end{array}$ & UHPLC-MS/MS & [131] \\
\hline Plasma & $\mathrm{AD}(\mathrm{n}=10), \operatorname{MCI}(\mathrm{n}=10)$ and control $(\mathrm{n}=10)$ subjects & Phospholipid profiling & HPLC-LTQ Orbitrap & [132] \\
\hline Plasma & AD patients $(n=26)$ and control subjects $(n=26)$. & Lipid profiling & QqQ-MS/MS & [133] \\
\hline CSF and Plasma & $\begin{array}{l}\text { Training set (CSF and plasma): AD patients }(n=10) \text { and control subjects }(n=10) \text {. } \\
\text { Validation set (Plasma): } A D(n=41), \operatorname{MCI}(n=26) \text { and control }(n=42) \text { subjects. }\end{array}$ & Steroid profiling & $\begin{array}{l}\text { HPLC-Q/MS } \\
\text { LTQ Orbitrap }\end{array}$ & [139] \\
\hline $\begin{array}{l}\text { Post-mortem human brain } \\
\text { Post-mortem mice brain }\end{array}$ & $\begin{array}{l}\text { AD patients }(n=30) \text { and control subjects }(n=14) \text {. } \\
\text { APPswedish mice }(n=5) \text { and control mice }(n=8) \text {. }\end{array}$ & Phospholipid profiling & FIA ${ }^{\mathrm{a}}-\mathrm{MS} / \mathrm{MS}$ & [150] \\
\hline
\end{tabular}

